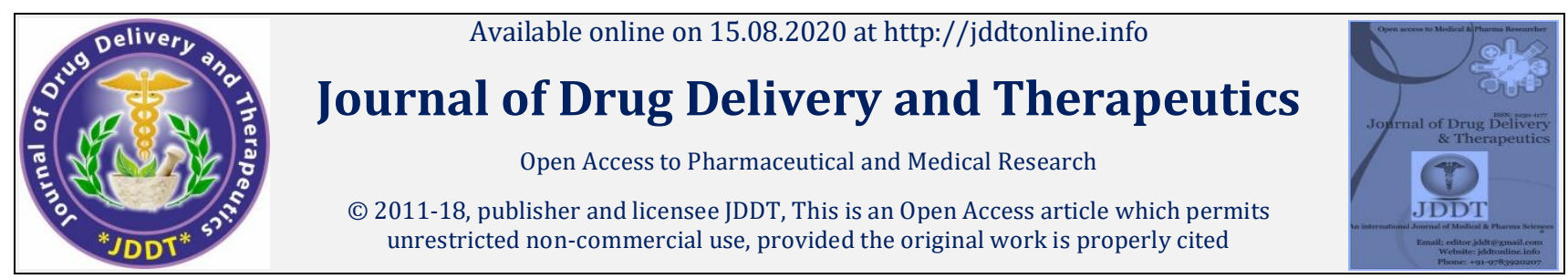

Open $\odot$ Access

Case Report

\title{
A Case Report on Idiopathic Severe Bullous Pemphigoid
}

\section{Mohammadi Fizza Khan*, Zoha Sultana, Baleeqhuddin Mohammed, Ali Salman Mir, Faizan Abdullah Md.}

Department of Pharmacy Practice, Deccan School of Pharmacy Nampally, Hyderabad, Telangana 500001, India

\begin{abstract}
Bullous Pemphigoid (BP) is an autoimmune disorder which exploits the immune system and affecting sub-epidermal region of skin causing mild itching to infection and blistering of sub-epidermal region. Clinical presentations are pruritis, urticarial, papular lesions. These la ter evolve to bullae in weeks to months and are typically present in the axillae, on the flexor surface of the forearms, medial thighs, trunk, and abdomen. The treatment for bullous pemphigoid is systemic corticosteroids, topical steroids in combination with nicotinamide plus tetracycline, minocycline or doxycycline have shown success in multiple cases. Immunosuppressive therapy is used when steroids do not contr ol the disease or if patients have contraindications for systemic corticosteroid treatments. Patient was brought to emergency department with chief complaints itching, redness, bullous lesion all over the body for 2 months. Oral complaints including solitary erosion seen on right side of buccal mucosa, pharyngeal erythema. Laboratory investigations were carried out. Patient was diagnosed based on physical examination. Patient was provided with adequate treatment and counseling.
\end{abstract}

Keywords: Bullous Pemphigoid, corticosteroid, Autoimmune disorder, sub-epidermal region.

Article Info: Received 17 June 2020; Review Completed 24 July 2020; $\quad$ Accepted 29 July 2020; Available online 15 August 2020

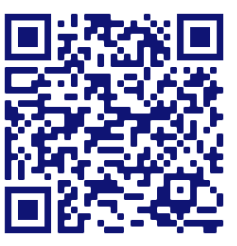

Cite this article as:

Mohammadi FK, Zoha S, Baleeqhuddin M, Ali SM, Faizan AM, A Case Report on Idiopathic Severe Bullous Pemphigoid, Journal of Drug Delivery and Therapeutics. 2020; 10(4-s):223-225 http://dx.doi.org/10.22270/jddt.v10i4-s.4311

*Address for Correspondence:

500001, India

Mohammadi fizza khan, Department of Pharmacy Practice, Deccan School of Pharmacy Nampally, Hyderabad, Telangana

\section{INTRODUCTION:}

Bullous Pemphigoid (BP) is an autoimmune disorder which exploits the immune system and affecting sub-epidermal region of skin causing mild itching to infection and blistering of sub-epidermal region. Bullous Pemphigoid is a rare dermatological disorder which can be seen in all age groups but mainly affecting elderly patients. ${ }^{1}$

Etiology:-

Many cases of bullous pemphigoid are due to autoantibodies against proteins arranged at the dermal-epidermal junction. Drug-induced bullous pemphigoid occurs up to 3 months after medication initiation and is usually noted during a younger to older subset of patients. Drugs which trigger this reaction are diuretics such as furosemide and spironolactone, NSAIDs, amoxicillin, PD-1/PD-L1 inhibitors, gliptins, and TNF-alpha inhibitors. ${ }^{2}$

Pathophysiology:-

There are 2 main components to the pathophysiology of BP: immunologic and inflammatory. The immunologic elements comprise autoantibodies against 2 parts of the basal keratinocyte hemidesmosomal proteins BP antigen 230 (BPAG1) and BP antigen 180 (BPAG2 or type XVII collagen) ${ }^{3}$
These antigens play an essential part in the adhesion complexes that promote epithelial-stromal adhesion. When autoantibodies bind to their target antigen, the inflammatory component follows which then activates complement and mast cells. This causes neutrophils and eosinophils to release a variety of inflammatory cells resulting in the release of proteolytic enzymes that damage the dermal-epidermal junction ${ }^{4}$

Clinical Presentation: -

In the prodromal phase, patients may experience moderateto-severe pruritus alone or associated with urticarial, papular lesions. ${ }^{5}$ This later evolves to bullae in weeks to months and are typically present in the axillae, on the flexor surface of the forearms, medial thighs, trunk, and abdomen. Approximately $20 \%$ of patients will have neither bullae nor erosions at time of presentation ${ }^{6}$.

Constitutional symptoms are uncommon, except in widespread, severe disease. The bullous phase characteristically presents with vesicles and bullae on a background of normal or erythematous skin. The blisters are tense, up to 1 to 4 centimeters in diameter, and sometimes hemorrhagic. They typically contain clear fluid and should persist for several days before leaving erosions and crusts. 
Unlike pemphigus vulgaris, the Nikolsky sign is negative in typical cases of bullous pemphigoid. ${ }^{7}$

Standard Treatment: -

The treatment for bullous pemphigoid is systemic corticosteroids, but treatment ultimately depends on comorbidities and extent of disease. For localized disease, less than $20 \%$ body surface area in an elderly patient, super potent topical steroids such as clobetasol may be used. 8 Topical steroids in combination with nicotinamide plus tetracycline, minocycline or doxycycline have shown success in multiple cases. ${ }^{9}$

A systemic prednisolone at a dose of $0.5-1.0 \mathrm{mg} / \mathrm{kg}$ per day is recommended. This dose of systemic corticosteroids controls the disease within approximately fortnight and should be slowly tapered over six to nine months or longer. This treatment regimen is limited by patient age, comorbidities and side effects. ${ }^{10}$

Immunosuppressive therapy is used when steroids do not control the disease or if patients have contraindications for systemic corticosteroid treatments. Alternative agents include azathioprine, mycophenolate mofetil, methotrexate, chlorambucil, and cyclophosphamide. If all other treatments fail, IVIG, anti-CD20 (rituximab) or omalizumab can be used for treatment-resistant cases. 10

\section{CASE REPORT:}

A 72 year old male patient who is hypertensive was brought to the emergency department of the hospital with chief complaint of itching, redness, bullous lesion all over the body for 2 months.

Oral complaints including solitary erosion seen on right side of buccal mucosa, pharyngeal erythema.

These lesions started two months back. Firstly, these lesions were seen on forehead which gradually developed into blisters and are progressive in nature. Further progressing to face, upper limb, lower limb, trunk, this eroded in 3 days and crusted in a week.

\section{INVESTIGATIONS:-}

Renal function tests were reported normal.

Liver function tests were reported normal.

\section{HAEMATOLOGICAL TEST: -}

White Blood Cells:- 13000 cells/cumm (Normal range: 4000-11000 cells/cumm)

Lymphocytes: - 15.7\% (Normal range: - 20\%-40\%)

Haemoglobin value:- $10.3 \mathrm{~g} / \mathrm{dL}$ (Normal range: - 11-17 g/dL)

Mean Corpuscular Volume: - 78.3 fL (81-101 fL)

Mean Corpuscular haemoglobin: - 25.4 picogram(pg) (Normal value: - 27-32 pg)

Hematocrit : - 31.7\% (Normal value: - 40.7-50.3\%)

\section{COMPLETE URINE EXAMINATION: -}

All parameters are normal except for the traces of albumins were seen in urine examination.

\section{DIFFERENTIAL DIAGNOSIS: -}

Physical examination like pruritus, papular lesion, blister all over the body (forearms, face, upper limbs, lower limbs, abdomen). Nikolsky sign is negative. Based on physical examination of blisters, it had been diagnosed as Bullous Pemphigoid(BP).

\section{TREATMENT: -}

Upon admission, the patient was provided with intravenous dexamethasone $4 \mathrm{mg}$ twice a day, intravenous pheniramine $2 . .25 \mathrm{mg}$ twice a day, intravenous pantoprazole $40 \mathrm{mg}$ once a day, tablet doxycycline $100 \mathrm{mg}$ once a day, tablet linezoid $600 \mathrm{mg}$ twice a day, tablet nicotinamide $250 \mathrm{mg}$ twice a day, tablet calcium with vitamin D3 $500 \mathrm{mg}$ once a day, tablet ferrous Ascorbate + folic acid once a day, tablet fluconazole $150 \mathrm{mg}$ once a day, syrup Lactulose $15 \mathrm{ml}$ once a day, KMnO4 compression thrice a day, Mupirocin Ointment, Clobetasol $(0.005 \% \mathrm{w} / \mathrm{w})+$ Fusidic acid $(2 \% \mathrm{w} / \mathrm{w})$. The patient was moved to isolation ward as a precautionary measure.

\section{OUTCOME AND FOLLOW-UP:}

The patient was kept under observation for 8 days. The patient had shown signs of improvement upon treatment. The patient should be closely monitored and counselled regarding the disease and prognosis of disease

\section{DISCUSSION:}

Bullous pemphigoid is chronic blistering of skin, it starts with mild itching and prognosis may lead to blistering and infections,BP is an autoimmune condition.

This patient came with the complaints of itching, redness, solitary erosion seen on right side of buccal mucosa, bullous lesion all over the body for 2 months. And was provided with corticosteroids, anti-histamine,antibiotics,anti- fungal, multivitamins systematic therapy ,

Tropically the patient was provided with potassium permanganate compression which is gold standard in management of Bullous pemphigoid along with potassium permanganate topical antibiotic, topical glucocorticoids was provided

During the discharge the patient and attenders were counselled in layman's language regarding the disease conditions, prognosis of disease, application of topical medications, adherence to the medications, nonpharmacological remedies and was advised to review back to the dermatologist as directed.

\section{ACKNOWLEDGEMENT:}

Authors would like to thank the staff of the Department of general medicine, Owaisi hospital and research centre.

\section{REFERENCES:}

1. Vaillant L, Bernard P, Joly P, Prost C, Labeille B, Bedane C, Arbeille B, Thomine E, Bertrand P, Lok C, Roujeau JC. Evaluation of clinical criteria for diagnosis of bullous pemphigoid. French Bullous Study Group. Arch Dermatol. 1998 Sep; 134(9):1075-80.

2. Stavropoulos PG, Soura E, Antoniou C. Drug-induced pemphigoid: a review of the literature. J Eur Acad Dermatol Venereol. 2014 Sep; 28(9):1133-40

3. Giudice GJ, Emery DJ, Diaz LA. Cloning and primary structural analysis of the bullous pemphigoid autoantigen BP180. J. Invest. Dermatol. 1992 Sep; 99(3):243-50

4. Stanley JR, Tanaka T, Mueller S, Klaus-Kovtun V, Roop D. Isolation of complementary DNA for bullous pemphigoid antigen by use of patients' autoantibodies. J. Clin. Invest. 1988 Dec; 82(6):1864-70

5. Alonso-Llamazares J, Rogers RS, Oursler JR, Calobrisi SD. Bullous pemphigoid presenting as generalized pruritus: observations in six patients. Int. J. Dermatol. 1998 Jul; 37

6. Di Zenzo G, Della Torre R, Zambruno G, Borradori L. Bullous pemphigoid: from the clinic to the bench. Clin. Dermatol. 2012 Jan-Feb; 30(1):3-16.

7. Baigrie D, Nookala V. Bullous Pemphigoid. [Updated 2019 Dec 17]. In: StatPearls [Internet]. Treasure Island (FL): StatPearls 
Publishing; 2020 Jan-. Available from: https://www.ncbi.nlm.nih.gov/books/NBK535374/

8. Roujeau JC, Lok C, Bastuji-Garin S, Mhalla S, Enginger V, Bernard $P$. High risk of death in elderly patients with extensive bullous pemphigoid. Arch Dermatol. 1998 Apr; 134(4):465-9

9. Williams HC, Wojnarowska F, Kirtschig G, Mason J, Godec TR, Schmidt E, Chalmers JR, Childs M, Walton S, Harman K, Chapman A, Whitham D, Nunn AJ., UK Dermatology Clinical Trials Network BLISTER Study Group. Doxycycline versus prednisolone as an initial treatment strategy for bullous pemphigoid: a pragmatic, non-inferiority, randomised controlled trial. Lancet. 2017 Apr 22; 389(10079):1630-1638.

10. Bilgiç Temel A, Bassorgun CI, Akman-Karakaș A, Alpsoy E, Uzun S. Successful Treatment of a Bullous Pemphigoid Patient with Rituximab Who Was Refractory to Corticosteroid and Omalizumab Treatments. Case Rep Dermatol. 2017 Jan-Apr; 9(1):38-44 